\title{
LITHORISK.COM: the novel version of a software for calculating and visualizing the risk of renal stone
}

\author{
Martino Marangella ${ }^{1}\left[\right.$ Michele Petrarulo $^{2} \cdot$ Corrado Vitale $^{3} \cdot$ Piergiuseppe Daniele $^{4} \cdot$ Silvio Sammartano $^{5}$
}

Received: 27 May 2020 / Accepted: 29 October 2020 / Published online: 27 November 2020

(c) The Author(s) 2020

\begin{abstract}
Estimation of state of saturation with stone-forming salt represents a reliable tool to assess the overall risk. The available methods are based on computer-assisted ab initio calculations. Our earlier method URSUS was subsequently substituted by Lithorisk ${ }^{\circledR}$, a software including visualization of risk profiles. Unfortunately, Lithorisk does not adapt to new versions of Windows ${ }^{\circledR}$ and Macintosh ${ }^{\circledR}$ Apple, neither runs on smartphones or tablets. We propose a novel version of the software which can be directly used online on any device equipped by different operating systems. Upon online connection and after registration, the software is ready for unlimited accesses, in either Italian, English or French. After digiting input variables (urea and creatinine also included) in a fixed dashboard, state of saturation is promptly given. In addition to state of saturation ( $\beta$ ) with calcium oxalate, brushite and uric acid, $\beta$ struvite and cystine are available. Both input variables and $\beta$ results are graphically depicted as green or red horizontal bars to indicate recommended values. The software was implemented with equations allowing to omit sulphate and ammonium excretion for users with difficult access to these measurements. This simplified version, tested for $\mathrm{BCaOx}$ and $\mathrm{BB}$ sh on 100 urine samples showed close correlation with the full version. The software gives a list of total and free concentrations and soluble complex species distribution. Results can be printed or saved as PDF. So, we propose an easily accessible software to estimate state of saturation usable on any operating system and personal device.
\end{abstract}

Keywords State of saturation $\cdot$ Soluble complex species $\cdot$ Stability constant $\cdot$ Calcium oxalate $\cdot$ Brushite $\cdot$ Struvite . Cystine · Uric acid

\section{Introduction}

The essential condition for a renal stone to form is supersaturation of urine with respect to lithogenic salts [1-3]. While supersaturation fully defines some types of stone disease, i.e., cystine, uric acid, struvite stones, it is not sufficient

Silvio Sammartano-Deceased.

Martino Marangella

mmarangella@alice.it

1 Fondazione Scientifica Mauriziano Hospital, Turin, Italy

2 Kidney Stone Laboratory, Mauriziano Hospital, Turin, Italy

3 Nephrology and Dialysis Unit, Mauriziano Hospital, Turin, Italy

4 Department of Analytical Chemistry, University of Turin, Turin, Italy

5 Department of Inorganic Analytical and Physical Chemistry, Messina, Italy to explain calcium containing renal stones. In this subset, stones are thought to result from imbalance between promoters and inhibitors of crystal formation [4]. Therefore, in addition to thermodynamic processes, well described by the state of saturation, kinetic processes including nucleation, growth and aggregation, role of macromolecules and their effect on crystal cell interaction in renal tubules, are relevant for crystallization [5, 6]. However, despite extensive experimental studies on kinetics of crystallization, the methods proposed so far are complex, time consuming and not standard controlled. This is why a recent Consensus Conference did not recommend their use in clinical practice [7]. This also applies to so-called semi-empirical methods for estimating urine saturation which, therefore, are not extensively used [2]. Conversely, the measurement of the relative supersaturation, based on computer calculations, was shown to represent a simple and useful tool to manage patients and improve compliance to preventive treatment as well [8-14]. 
Years ago, we had developed our own method for calculating urine saturation with stone-forming salts, called URSUS and distributed as CD-ROM in our country [15]. This method used computer-assisted ab initio calculations to estimate the relative saturations ( $($ ) for calcium oxalate $(\mathrm{CaOx})$, brushite (Bsh) and uric acid (UA). While input variables were the same as those used by others, instead of thermodynamic stability constants, conditional stability constants of soluble complex species, reassessed at actual ionic strengths, were used [11]. To better support users in the interpretation of results, we subsequently produced Lithorisk ®, a software for both calculation and graphic visualization of risk profiles for stone formation [16]. However, this software cannot be changed so as to adapt to upcoming new versions of Windows $\AA$, nor it can work on Macintosh $\circledast$ Apple computer or run on smartphone or tablets. Therefore, we have developed a new software which can be directly used online on any device equipped by different operating systems. The software has been improved in that it now provides a reliable estimate of $\mathrm{BCaOx}$ and BBsh even if sulfate and ammonium measurements are not available. Also, the state of saturation with both struvite and cystine has been added in the calculations.

\section{Materials and methods}

The source code has been completely re-written based on the original files [11]. Despite some difficulties, we were able to simplify the use of the program by disposing an online connection. The interface presentation and the graphical output have been changed. The software cannot be downloaded but can be accessed directly online upon registration as a new user, and used on a personal device in either Italian, English or French language.

Each input variable must be digited in a fixed dashboard in the preferred units. If urine volume is available, input values, given as 24-h urine excretion, are automatically transformed as concentrations per liter. At any value, a green or red horizontal bar will correspond, to evidence normal or abnormal values according to their positive or negative effects on supersaturation, respectively. The sense of the effect conforms to arbitrary though widely accepted reference ranges, which are delimited by a thin yellow bar [2, 17-20]. Upper and lower limits for input data have been set to avoid erroneous input and will not be accepted by the software. At the end of calculation, patient's personal information can be added. To fulfill the privacy rules and assure safeness of the data, the measurements and results cannot be saved online, but can be printed or saved as PDF file on personal devices.

\section{Results}

Figure 1 illustrates and exemplifies a dashboard filled with input variables necessary to make one sample calculation. Both excretions of urea and creatinine are required. Urea measurements provide information about dietary protein intakes, whereas creatinine can be used to both normalize different parameters and verify correctness of urine collection. Other diet-related parameters are sodium, potassium and sulfate excretions. Inputs can be given in different units ( $\mathrm{mmol} / \mathrm{L}$ or $\mathrm{mg} / \mathrm{dL}$ ) conforming to the current laboratory reports. Upon completion of data entry, results of state of saturations will be given upon clicking on the bottom bar.

Results of $B$ which promptly appear are depicted as horizontal bars, green in case of $\beta<1$ for uric acid and struvite. Thresholds of normal range for calcium oxalate, brushite and cystine, denoted by a small yellow bar, are of course arbitrary, and refer to recommended levels of saturation emerging from the literature $[8,9,16-22]$. The sheet can be completed with personal information of the patients and finally can be printed or saved as PDF. In addition, by clicking on the Details gray bar, it is possible to get a list of total and free concentrations and soluble complex species distribution as well (Fig. 2). This option can be of particular interest for expert clinicians and basic scientists to be used for research purposes.

Many potential users had complained to be unable to use the first version of Lithorisk $₫$ because their laboratories did not supply measurements of inorganic sulphate and urinary ammonium. To obviate this drawback, in this last version, the software was implemented with equations, whereby estimates of the above components were derived, by means of multiple regression analysis, from measurements commonly available everywhere. Regression analysis was performed by using a previous database [23]. From this, we found that urea and phosphate were reliable predictor for sulphate and urea and creatinine for ammonium, according to the following equations (all parameters as $\mathrm{mmol} / 24 \mathrm{~h}$ ):

Inorganic Sulphate $=0.043$ Urea +0.125 Phosphate -1.53 , $r^{2}=0.76 p<0.0001 n=233$;

Ammonium $=0.215$ Creat +0.054 Urea +13.1 ,

$r^{2}=0.29 p<0.0001 n=233$.

To test the reliability of the above equations, we calculated $\mathrm{BCaOx}$ and $\mathrm{BBsh}$ using both actually measured and predicted values of sulphate and ammonium. The correspondence between the two sets of measures made on 100 urine collections appeared quite satisfactory as evidenced in Figs. 3 and 4. 
Fig. 1 Illustration of the dashboard filled with measurements from a sample $24 \mathrm{~h}$ urine. Units can be changed from $\mathrm{mg}$ to mmol and viceversa according to usual laboratory reports. Green or red bars indicate whether or not measurements are within a recommended arbitrary range. Results of the calculations of state of saturation with calcium oxalate, brushite, struvite, uric acid and cystine are shown in the bottom of the figure. Green or red bars indicate whether $\beta$ values are within a recommended arbitrary range. Patient's personal data can be given

\section{LITHORISK \\ Software per il calcolo \\ e la rappresentazione \\ grafica del rischio litogeno}
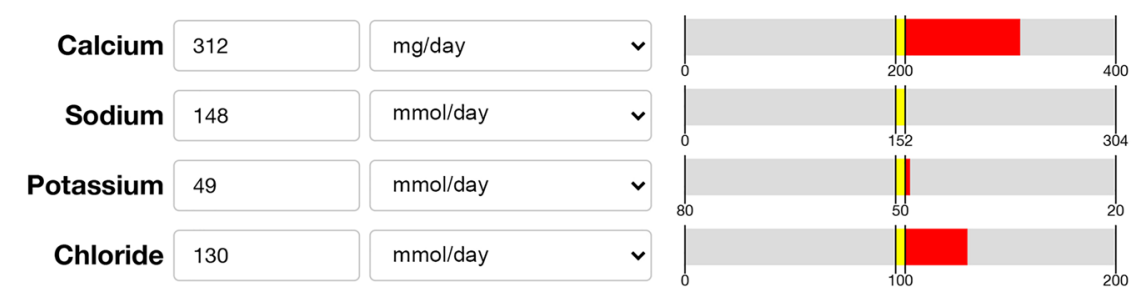

\begin{tabular}{rlr}
$\begin{array}{r}\text { Urinary } \\
\text { volume }\end{array}$ & 1 \\
Magnesium $100 \quad$ Ig/day & \multicolumn{1}{c}{ l/day }
\end{tabular}

Citrate 2
Ammonium 40

\begin{tabular}{|c|c|c|c|}
\hline Ammonium & 40 & $\mathrm{mmol} /$ day & $\checkmark$ \\
\hline Phosphate & 28 & $\mathrm{mmol} / \mathrm{day}$ & $\checkmark$ \\
\hline Sulphate & 25 & $\mathrm{mmol} / \mathrm{day}$ & $\checkmark$ \\
\hline Oxalate & 0.2 & $\mathrm{mmol} / \mathrm{day}$ & $\checkmark$ \\
\hline
\end{tabular}

Uric acid 500
Cystine 156
pH 6

Urea 15.3
Creatinine 1.06

$\mathrm{mg} /$ day

$\mu \mathrm{mol} / \mathrm{L}$

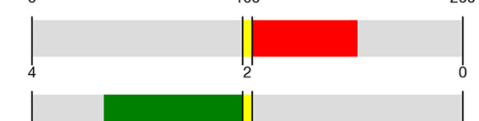

$\mathrm{mmol} / \mathrm{day} \quad$ v
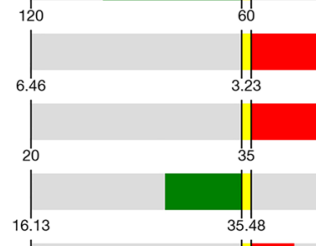

$\checkmark$

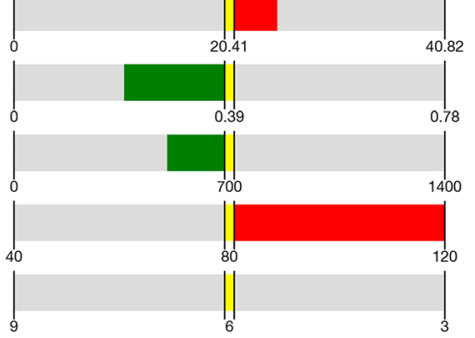

g/day

g/day

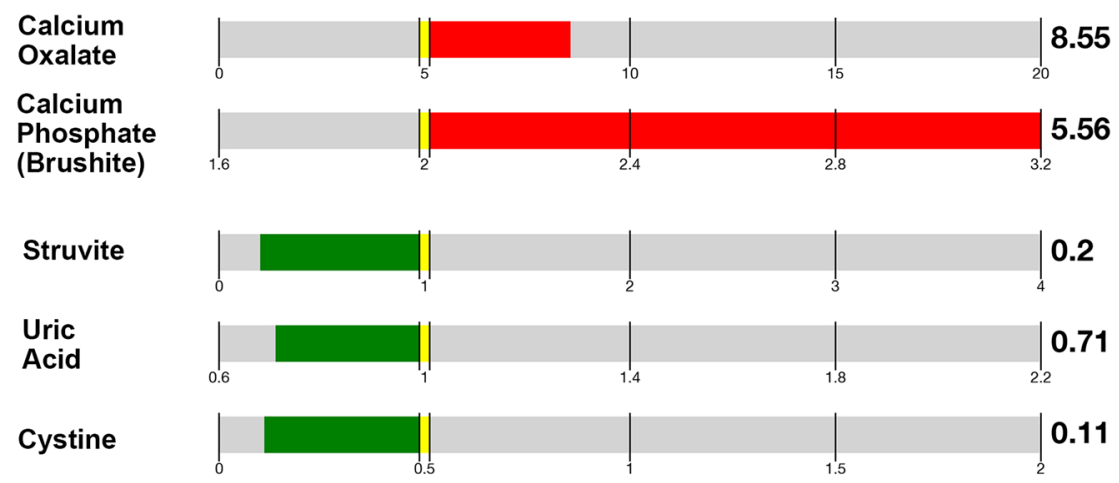

Graph obtained via the Lithorisk® software. No sensitive data has been saved.. Riproduction forbidden. For info: www.lithorisk.com 


\section{Free Concentrations}

\begin{tabular}{|l|l|l|l|l|}
\hline Component & Concentration & S.D. & \%[free/total] & S.D. \\
\hline & $\mathrm{mmol} / \mathrm{l}$ & & & \\
\hline $\mathrm{Ca}$ & 1.700 & 0.066 & 51.0 & 2.0 \\
\hline $\mathrm{Mg}$ & 0.845 & 0.036 & 48.3 & 2.1 \\
\hline $\mathrm{Na}$ & 65.381 & 0.989 & 98.1 & 1.5 \\
\hline $\mathrm{K}$ & 26.045 & 0.655 & 97.7 & 2.5 \\
\hline $\mathrm{NH} 4$ & 21.379 & 0.549 & 94.3 & 2.4 \\
\hline Ox & 0.105 & 0.004 & 43.9 & 1.7 \\
\hline Cit & 0.125 & 0.006 & 7.2 & 0.4 \\
\hline HPO4 & 0.615 & 0.041 & 4.6 & 0.3 \\
\hline S04 & 6.202 & 0.200 & 65.1 & 2.1 \\
\hline
\end{tabular}

I (ionic strenght) $=0.122$ sigma $=0.001$

\section{Urine Saturation}

\begin{tabular}{|l|l|l|}
\hline Component & Value & LogKsp \\
\hline $\mathrm{CaOx}$ & 8.98 & -7.70 \\
\hline $\mathrm{CaHPO4}$ & 0.72 & -5.84 \\
\hline MgNH4PO4 & 0.01 & -11.30 \\
\hline BetaAU & 1.34 & -8.58 \\
\hline
\end{tabular}

Species Concentrations

\begin{tabular}{|c|c|c|c|c|c|}
\hline Species & Concentration & S.D. & Formation & S.D. & Log (beta) \\
\hline & $\mathrm{mmol} / \mathrm{l}$ & & Percentages (*) & & \\
\hline$[H(o x)]$ & 0.003 & 0.000 & $1.2 \mathrm{ox}$ & 0.1 & 3.99 \\
\hline$[\mathrm{H}(\mathrm{cit})]$ & 0.231 & 0.014 & 13.3 cit & 0.8 & 5.83 \\
\hline [H2(cit)] & 0.014 & 0.001 & 0.8 cit & 0.1 & 10.16 \\
\hline [H2(P04)] & 11.810 & 0.315 & $88.6 \mathrm{HPO} 4$ & 2.4 & 6.84 \\
\hline [Calox $)]$ & 0.045 & 0.004 & 18.9 ox & 1.8 & 2.40 \\
\hline [Ca(cit)] & 0.768 & 0.037 & 44.3 cit & 2.1 & 3.56 \\
\hline [CaH(cit)] & 0.046 & 0.007 & 2.7 cit & 0.4 & 7.90 \\
\hline [CaH(PO4)] & 0.099 & 0.012 & $0.7 \mathrm{HPO} 4$ & 0.1 & 1.98 \\
\hline [CaH2(PO4)] & 0.246 & 0.050 & $1.8 \mathrm{HPO} 4$ & 0.4 & 7.93 \\
\hline [Ca(SO4)] & 0.429 & 0.030 & $4.5 \mathrm{SO} 4$ & 0.3 & 1.61 \\
\hline [Mglox $]]$ & 0.046 & 0.004 & $19.2 \mathrm{ox}$ & 1.6 & 2.71 \\
\hline [Mg(cit)] & 0.420 & 0.027 & 24.3 cit & 1.6 & 3.60 \\
\hline$[\mathrm{MgH}(\mathrm{cit})]$ & 0.011 & 0.002 & 0.6 cit & 0.1 & 7.58 \\
\hline [MgH(PO4)] & 0.068 & 0.008 & $0.5 \mathrm{HPO} 4$ & 0.1 & 2.12 \\
\hline$[\mathrm{MgH} 2(\mathrm{PO} 4)]$ & 0.165 & 0.033 & $1.2 \mathrm{HPO} 4$ & 0.2 & 8.06 \\
\hline [Mg(S04)] & 0.194 & 0.017 & 2.0504 & 0.2 & 1.57 \\
\hline [Na(ox)] & 0.022 & 0.002 & 9.4 ox & 1.0 & 0.51 \\
\hline [Na(cit)] & 0.042 & 0.005 & $2.4 \mathrm{cit}$ & 0.3 & 0.71 \\
\hline$[\mathrm{NaH}(\mathrm{cit})]$ & 0.020 & 0.004 & $1.1 \mathrm{cit}$ & 0.2 & 5.95 \\
\hline [NaH(PO4)] & 0.185 & 0.024 & $1.4 \mathrm{HPO} 4$ & 0.2 & 0.66 \\
\hline [Na(SO4)] & 1.017 & 0.108 & $10.7 \mathrm{SO} 4$ & 0.2 & 0.66 \\
\hline [K(ox)] & 0.007 & 0.001 & $3.0 \mathrm{ox}$ & 0.4 & 0.42 \\
\hline$[K(c i t)]$ & 0.012 & 0.002 & 0.7 cit & 0.1 & 0.58 \\
\hline [KH(cit)] & 0.003 & 0.001 & 0.2 cit & 0.0 & 5.54 \\
\hline [KH(PO4)] & 0.049 & 0.007 & $0.4 \mathrm{HPO} 4$ & 0.0 & 0.49 \\
\hline [K(SO4)] & 0.550 & 0.062 & $5.8 \mathrm{SO} 4$ & 0.7 & 0.53 \\
\hline [NH4(ox)] & 0.010 & 0.001 & 4.3 ox & 0.5 & 0.67 \\
\hline [NH4(cit)] & 0.025 & 0.006 & 1.5 cit & 0.3 & 0.98 \\
\hline [NH4H(cit)] & 0.015 & 0.003 & 0.9 cit & 0.2 & 6.32 \\
\hline [NH4H(P04)] & 0.096 & 0.012 & $0.7 \mathrm{HPO} 4$ & 0.1 & 0.86 \\
\hline [NH4H(SO4)] & 1.141 & 0.114 & $12.0 \mathrm{SO} 4$ & 1.2 & 0.93 \\
\hline
\end{tabular}

(*) The formation percentages are calculated with respect to the ligand.

Fig. 2 Species distribution in urine from a single patient, are displayed after clicking of the Details bar (not shown in figure). The whole record can be printed or saved on personal device

\section{Discussion}

Nephrolithiasis is a disease with a great epidemiological impact, since up to $10 \%$ of the general population is expected to form at least one stone in their lifespan [24] and, in a considerable part of cases, it recurs [25]. This disease can be successfully managed by integrating urological and medical approach, the latter aimed at reducing stone recurrence rate [26]. Metabolic evaluation stands as a crucial means to assist physicians in patients' management $[7,19$, 20]. Despite extensive studies, much remains to understand about pathogenesis of stone disease, at least concerning calcium nephrolithiasis. An imbalance between saturation and inhibition in urine environment was suggested as a crucial risk factor [4]. While studies on inhibitors are still weakened by a number of theoretical and practical flaws, measurements of state of saturation have widely spread, appearing as an easy and reliable tool. It is well accepted that state of saturation cannot be used to distinguish between stone formers and non-stone formers, nor between single and recurrent stone formers, in that a wide overlapping of data has been found in virtually all saturation studies $[11,21,27]$. As a matter of fact, while measurements of excretion of urine components inform us about derangements in metabolic pathways and dietary disorders, state of saturation gives a view of the propensity for crystals to form with the consequent risk of stones.

Some contend that to achieve saturation estimates requires that many urinary components be measured with the consequent increase in cost. This explains why several urine-based indices have been proposed trying to simplify the assessment of the stone risk. These include the Tiselius Index [28], the 


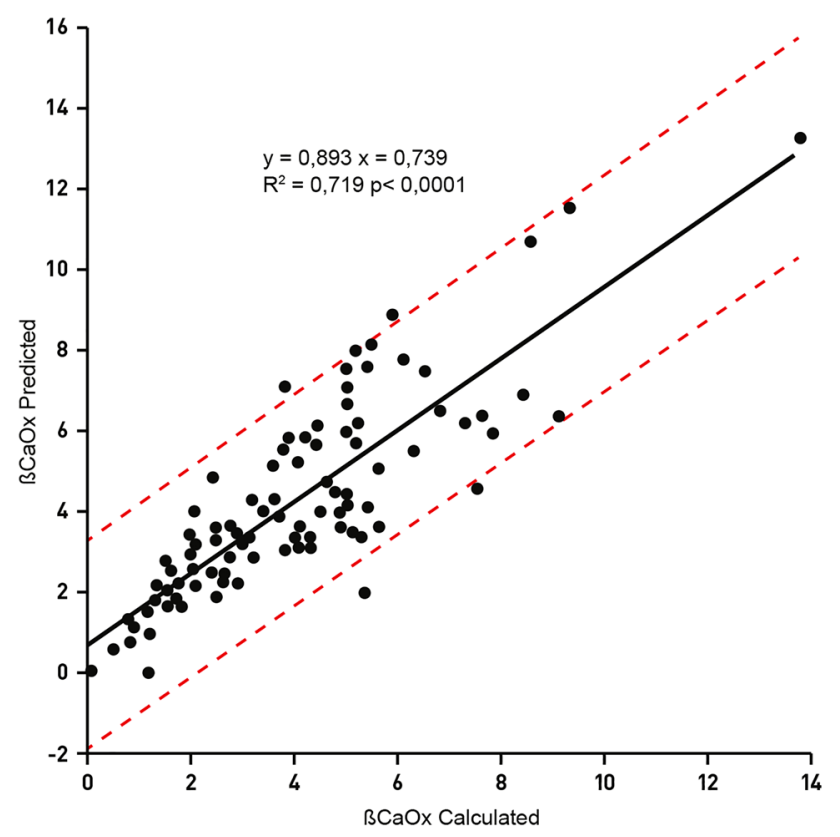

Fig. 3 Correlation between measurements of calcium oxalate relative saturation $(\mathrm{BCaOx})$ carried out using sulphate and ammonium excretions either measured or derived by regression analysis reported in Eqs. (1) and (2). Correlation includes 100 urine samples. Dotted lines indicate $95 \%$ confidence intervals

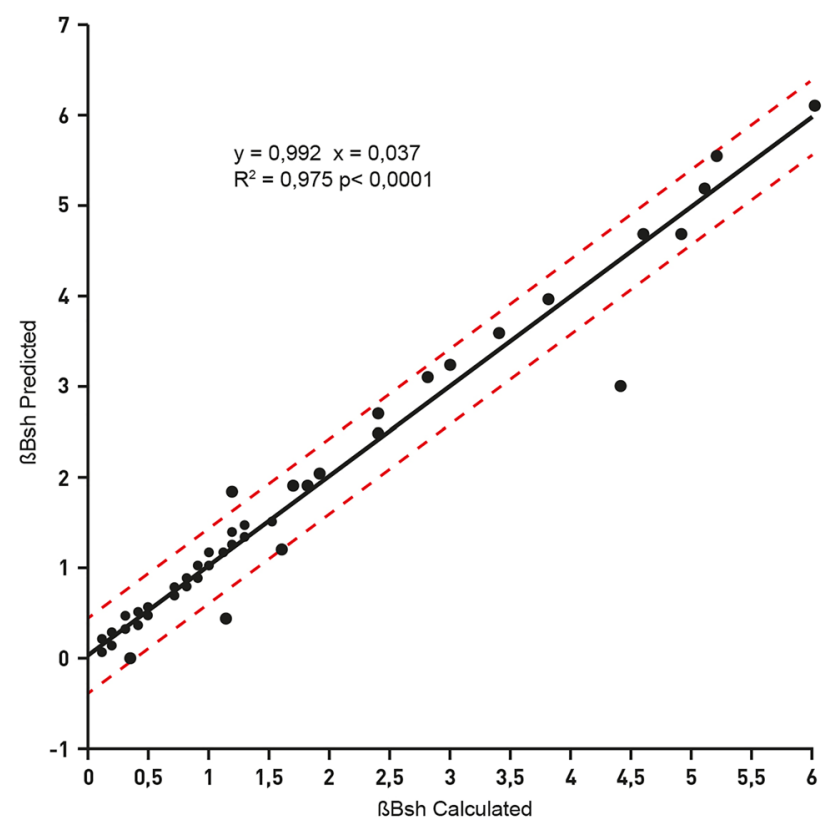

Fig. 4 Correlation between measurements of brushite relative saturation (BBsh) carried out using sulphate and ammonium excretions either measured or derived by regression analysis reported in Eqs. (1) and (2). Correlation includes 100 urine samples. Dotted lines indicate $95 \%$ confidence intervals
Robertson PSF index [29], the Bonn-Risk Index [30], the upper limit of osmolality proposed by Porowski et al. [31] and maybe many others. However, none of these has widely diffused, so that they warrant confirmation by clinical trials.

Herein, we report a new version of the software Lithorisk ${ }^{\circledR}$ which is characterized by several novelties:

1. There is a direct access to the software through web on users' devices, including PC and laptop, tablets and smartphones, independently of the operating system. The software is based on the earlier version [16] and uses the same stability constants of soluble complexes handled with the same math principles.

2. There is a completely renewed graphic presentation.

3. It is now possible to get estimates of struvite and cystine saturations.

4. Species distribution is available, including concentration and percentage of both cations and anions and soluble complexes as well. In expert hands, this could be an important option to evaluate the impact of varying ion concentrations on species distribution to optimize effects on state of saturation. For instance, it may be relevant to assess effects of different citrate and magnesium concentrations on ionic equilibria and proton concentration [22].

5. The new software is equipped with subroutines that generate $\beta$ values even omitting the sulphate and ammonium concentrations. Despite their marginal influence on the calculations, sulfate and ammonium determinations are generally included in ab initio calculations, including ours. Indeed, changing concentrations from the lower to upper limits of normal distribution, the effects become not irrelevant. For instance, changing sulphate concentration from 10 to $40 \mathrm{mmol} / \mathrm{L}$, leaving other components unchanged, results in $22 \%$ variation of $\mathrm{BCaOx}$. The correlation of Eq. (2) (see "Results" session), concerning ammonium, is not much close. However, this impacts only marginally the calculations of $\mathrm{BCaOx}$ and $\mathrm{BBsh}$ because of the weak stability constant of ammonium with corresponding ligands in urine [11]. Of course, ammonium may have greater influence on BStruvite, and in this case, we do not recommend to utilize the simplified version that uses calculated and not measured ammonium concentrations.

To ease the task of producing this version of Lithorisk ${ }^{\circledR}$, it was decided to maintain the original list of soluble complexes. This may suffice in the routine management of patients, namely, to improve and control their compliance to treatment [7]. In addition, the prompt visualization of the results allows to simulate beneficial or detrimental effects on the stone risk generated by changes in urine chemistry and volume. For instance, the software can be used to tailor 
values of urine volume or calcium or other components that will result in safer saturation levels in individual patients. Therefore, this new program is essentially similar to previous others that measure state of saturation, including our previous one. We had reported a nice correspondence between our results and those obtained with EQUIL 2 [11]. The program has not been compared to the more recent JESS [13. 14] which includes mixed calcium-citrate-phosphate species and has been reported to yield different results from previous ones at least at higher urine pHs [32]. Work is in progress to assess whether integrating our program with the above complex species, or weak urea complexes [33], or phytate [34], will affect results in a significant way.

In conclusion, the essential novelty of this software is that it can be easily available for use in any operating systems and personal devises. Also, the great simplification of the input variable procedure, including the option to change units, and the novel graphical visualization of risk profiles are likely to ease the use and widen the understanding of the concept of saturation in the general practice of stone disease.

Acknowledgments The authors thank Peter Neus for the invaluable technical assistance in the preparation of the software, and Salvatore Piazzolla who restyled the Figures.

Funding This study was funded by Biohealth Italia srl. Turin (Italy).

Data availability Biohealth Italia srl Lithocenter data base.

\section{Compliance with ethical standards}

Conflict of interest Martino Marangella, Pier Giuseppe Daniele and Michele Petrarulo received research grants from Biohealth Italia srl. Corrado Vitale declares no conflict of interest. Silvio Sammartano (deceased) had no conflict of interest.

Open Access This article is licensed under a Creative Commons Attribution 4.0 International License, which permits use, sharing, adaptation, distribution and reproduction in any medium or format, as long as you give appropriate credit to the original author(s) and the source, provide a link to the Creative Commons licence, and indicate if changes were made. The images or other third party material in this article are included in the article's Creative Commons licence, unless indicated otherwise in a credit line to the material. If material is not included in the article's Creative Commons licence and your intended use is not permitted by statutory regulation or exceeds the permitted use, you will need to obtain permission directly from the copyright holder. To view a copy of this licence, visit http://creativecommons.org/licenses/by/4.0/.

\section{References}

1. Finlayson B (1977) Calcium stones: some physical and clinical aspects. In: David DS (ed) Calcium metabolism in renal failure and nephrolithiasis, chap 10. Wiley, New York, pp 337-382

2. Pak CY (1969) Physicochemical basis for formation of renal stones of calcium phosphate origin: calculation of the degree of saturation of urine with respect to brushite. J Clin Invest 48:1914-1922

3. Coe FL, Parks JH, Asplin JR (1992) The pathogenesis and treatment of kidney stones. N Engl J Med 327:1141-1152

4. Robertson WG, Peacock M, Marshall RW, Marshall DH, Nordin BE (1976) Saturation-inhibition index as a measure of the risk of calcium oxalate stone formation in the urinary tract. N Engl J Med 294:249-252

5. Khan SR (2011) Crystal/cell interaction and nephrolithiasis. Arch Ital Urol Androl 83:1-5

6. Rimer JD, Kolbach-Mandel AM, Ward MD et al (2017) The role of macromolecules in the formation of kidney stones. Urolithiasis 45:57-74

7. Gambaro G, Croppi E, Coe F et al (2016) Consensus Conference Group. Metabolic diagnosis and medical prevention of calcium nephrolithiasis and its systemic manifestations: a consensus statement. J Nephrol 29:715-734

8. Robertson WG, Peacock M, Nordin BE (1968) Activity products in stone-forming and non-stone-forming urine. Clin Sci 34:579-594

9. Weber DV, Coe FL, Parks JH, Dunn MS, Tembe V (1979) Urinary saturation measurements in calcium nephrolithiasis. Ann Intern Med 90:180-184

10. Werness PG, Brown CM, Smith LH, Finlayson B (1985) EQUIL2. a basic computer program for the calculation of urinary saturation. J Urol 134:1242-1246

11. Marangella M, Daniele PG, Ronzani M, Sonego S, Linari F (1985) Urine saturation with calcium salts in normal subjects and idiopathic calcium stone-formers estimated by an improved computer model system. Urol Res 13:189-193

12. Brown CM, Ackermann DK, Purich DL (1994) EQUIL93: a tool for experimental and clinical urolithiasis. Urol Res 22:119-126

13. May PM, Murray K (1991a) JESS, a joint expert speciation system-1. Talanta 38:1409-1417

14. May PM, Murray K (1991b) JESS, a joint expert speciation system-II, The thermodynamic data base. Talanta 38:1419-1426

15. Daniele PG, De Stefano C, Marangella M, Rigano C, Sammartano $S$ (1989) Ursus: A computer program for urine speciation. Biochim Clin 13:507-510

16. Marangella M, Petrarulo M, Daniele PG, Sammartano S (2002) LithoRisk: a software for calculating and visualising nephrolithiasis risk. G Ital Nefrol 19:693-698

17. Preminger GM (1989) The metabolic evaluation of patients with recurrent nephrolithiasis: a review of comprehensive and simplified approaches. J Urol 141:760-763

18. Hess B, Hasler Strub U, Ackermann D, Jaeger P (1997) Metabolic evaluation of patients with recurrent calcium nephrolithiasis. Nephrol Dial Transplant 12:1362-1368

19. Sakhaee K, Maalouf NM, Sinnott B (2012) Clinical review. Kidney stones 2012: pathogenesis, diagnosis, and management. J Clin Endocrinol Metab. 97:1847-1860

20. Goldfarb DS, Arowojolu O (2013) Metabolic evaluation of firsttime and recurrent stone formers. Urol Clin N Am 40:13-20

21. Asplin JR, Parks JH, Coe FL (1997) Dependence of upper limit of metastability on supersaturation in nephrolithiasis. Kidney Int 52:1602-1608

22. Kavanagh JP (2006) Supersaturation and renal precipitation: the key to stone formation? Urol Res 34:81-85

23. Esperto F, Marangella M, Trinchieri A, Petrarulo M, Miano R (2018) A Multiregional italian cohort of 24-hour urine metabolic evaluation in renal stone formers. Minerva Urol Nefrol 70:87-94

24. Pearle MS, Calhoun EA, Curhan GC (2005) Urologic diseases in america project: urolithiasis. J Urol 173:848-857 
25. Trinchieri A, Ostini F, Nespoli R, Rovera F, Montanari E, Zanetti G (1999) A prospective study of recurrence rate and risk factors for recurrence after a first renal stone. J Urol 162:27-30

26. Pearle MS, Goldfarb DS, Assimos DG et al (2014) Medical management of kidney stones: AUA guideline. J Urol 192:316-324

27. Rodgers LA (2014) Urinary saturation: casual or causal risk factor in urolithiasis? BJU Int 114:104-110

28. Tiselius HG (1999) Factors influencing the course of calcium oxalate stone disease. Eur Urol 36:363-370

29. Robertson WG (2003) A risk factor model of stone-formation. Front Biosci 8:s1330-1338

30. Lewandowski S, Rodgers AL, Laube N, von Unruh G, Zimmermann D, Hesse A (2005) Oxalate and its handling in a low stone risk vs a stone-prone population group. World J Urol 23:330-333

31. Porowski T, Kirejczyk JK, Mrozek P et al (2019) Upper metastable limit osmolality of urine as a predictor of kidney stone formation in children. Urolithiasis 47:155-163
32. Rodgers AL, Allie-Hamdulay S, Jackson G (2006) Therapeutic action of citrate explained by chemical speciation: increase in $\mathrm{pH}$ is the determinant factor. Nephrol Dial Transplant 21:361-369

33. Daniele PG, De Robertis A, Sammartano S (1992) The effect of urea on the protonation of acetate, oxalate, malonate, citrate and sulfate in aqueous sodium, potassium, calcium chlporide and tetraethylammonium iodide. Anal Chim 82:503-515

34. Fakier S, Rodgers A, Jackson G (2019) Potential thermodynamic and kinetic roles of phytate as an inhibitor of kidney stone formation: theoretical modelling and crystallization experiments. Urolithiasis 47:493-502

Publisher's Note Springer Nature remains neutral with regard to jurisdictional claims in published maps and institutional affiliations. 